\title{
A Study of Mobile Internet User Generated Content Motivation
}

\author{
Shiying Zhang \\ Institute of Business \& Economic Research, Harbin University of Commerce, Harbin 150028, China \\ zhshyy@163.com
}

Keywords: Mobile Internet, UGC, Motivation

\begin{abstract}
This study discusses the motivation of mobile Internet user generated content (MIUGC). It divides four dimensions: subject level, system perception, social relations, and perceived risk, which includes 15 variables. Based on theoretical analysis, literature research, interviews, surveys and statistical analysis, it studies the key influence factors of MIUGC, which helps to motivate MIUGC better, promote the sharing of information and knowledge, attract more users and expand the self-media space more effectively in mobile network.
\end{abstract}

\section{Introduction}

The concept of User Generated Content (UGC) originates from Internet, which means users can display their own original content or provide it to other users through the Internet platform. The continuous development of mobile technology has brought great changes to people's life. The mobile terminal has become an important information processing platform that can be moved around. In the field of social media, the decline of PC utilization is obvious, while the usage time of mobile terminal increases rapidly. At present, social media applications emerge in an endless stream. In the era of Web 2.0, a lot of user-generated content is flooded with we-media. What factors influence the mobile Internet user generated content (MIUGC)? What are the dimensions? This study will deeply discuss the motivation of mobile Internet user generated content.

\section{Research Questions and Hypothesis}

Based on theoretical analysis and user interviews, this research divides the motivation of MIUGC into four dimensions: subject level, system perception, social relations, and perceived risk. Subject level mainly includes personality traits, cognitive style, self-efficacy, willingness to express \& record, self-value, altruism and external benefits; system perception includes perceived ease of use, perceived usefulness and perceived entertainment; social relations mainly includes social influence, social interaction, social identity and social trust.

1) Personality Traits (PT). According to long-term clinical experience, Jung ${ }^{[1]}$ believes that there are two different types of personality traits: introverted and extroverted. The extrovert may be sociable and crave stimulation, while the introvert presents the reverse. MIUGC is a kind of social interaction in a mobile environment where personality traits can be presented as in the reality. We suppose that the higher the user's extraversion is, the more their motivation for MIUGC is. Thus, we hypothesize

H1: Personality traits will have a positive impact on the MIUGC.

2) Need for Cognition (NC). Research shows cognitive needs are positively correlated with curiosity, intrinsic motivation, and openness to opinions. Thus, we hypothesize

H2: Need for cognition will have a positive impact on the MIUGC.

3) Self-Efficacy (SE). Self-efficacy is an individual's belief in his or her innate ability to achieve goals. People generally avoid tasks where self-efficacy is low, but undertake tasks where self-efficacy is high. The impact of self-efficacy of individuals using the Internet and related innovations on system utilization has been confirmed in lots of studies. Thus, we hypothesize 
H3: Self-efficacy will have a positive impact on the MIUGC.

4) Willingness to Express and Record (WER). Everyone has a desire to talk. Sometimes, the desire to express is hard to control. In this case, users may use the MIUGC platform they're used to to express their opinions. They also record an event or their moods at a certain moment in the MIUGC platform, because people are easy to forget and ignore some details. Thus, we hypothesize

H4: Willingness to express and record will have a positive impact on the MIUGC.

5) Self-worth (SW). Self-worth is at the highest level of Maslow's hierarchy of needs. When one feels that a certain behavior can achieve his self-worth, the willingness to continue the behaviors including generating content in mobile web will be stronger. Thus, we hypothesize

H5: Self-worth will have a positive impact on the MIUGC.

6) Altruism (AL). Altruism refers to the voluntary behavior that helps others to receive benefits. Recently, in many researches on user behavior related to knowledge sharing technologies, altruism has become a good research variable. Kwok \& $\mathrm{Gao}^{[2]}$ 's research shows that altruistic behavior is to encourage members to contribute knowledge in a point-to-point community. Thus, we hypothesize

H6: Altruism will have a positive impact on the MIUGC.

7) External Benefits (EB). External benefits refers to the rewards derived from MIUGC beyond individuals. For example, users can get more points, upgrade user ratings, and gain more network privileges through MIUGC. Thus, we hypothesize

H7: External benefits will have a positive impact on the MIUGC.

8) Perceived Usefulness (PU). According to the Technology Acceptance Model (TAM), perceived usefulness refers to the extent to which a user perceives a system to increase his efficiency. The research of Wei et al. ${ }^{[3]}$ has found that perceived usefulness has an important impact on the use of mobile Internet commerce. Thus, we hypothesize

H8: Perceived usefulness will have a positive impact on the MIUGC.

9) Perceived Ease of Use (PEU). In TAM, perceived ease of use refers to the extent to which a user perceives the system to save his effort. Many studies have verified the impact of perceived ease of use on the use of instant messaging technology. According to TAM, there are positive paths from perceived ease of use to perceived usefulness and from self-efficacy to perceived ease of use. Thus, we hypothesize

H9: Perceived ease of use will have a positive impact on the MIUGC.

H10: Perceived ease of use will have a positive impact on perceived usefulness.

H11: Self-efficacy will have a positive impact on perceived ease of use.

10) Perceived Entertainment (PE). Perceived entertainment is the extent to which an individual feels fun when participating in an activity. Agarwal \& Karahana ${ }^{[4]}$ used the variable of perceived entertainment to explain people's use of the Internet. Thus, we hypothesize

H12: Perceived entertainment will have a positive impact on the MIUGC.

11) Social Influence (SIF). The social influence was defined as the influence degree to which users perceives by other people or groups when use systems. Thus, we hypothesize

H13: Social influence will have a positive impact on the MIUGC.

12) Social Interaction(SIT). Social Interaction is the basic of man's social being. In the MIUGC platform, users are not independent, and communicate through forwarding, evaluation, etc. This relationship is attractive to a user. Thus, we hypothesize

H14: Social interaction will have a positive impact on the MIUGC.

13) Social Identity (SID). Social identity refers that mobile users seek their social status, social image identity and community belonging through MIUGC, and can be attributed to the respect demand in Maslow's hierarchy of needs. Thus, we hypothesize

H15: Social identity will have a positive impact on the MIUGC.

14) Social Trust (ST). Cook \& Wall ${ }^{[5]}$ pointed out that social trust is a good state of mind of having confidence in others' words and deeds, and subjectively attribute them to good. Some researches show that trust is a factor of perceived behavioral control. In our interviews, social trust was found to help users increase their altruism. Thus, we hypothesize

H16: Social trust will have a positive impact on the MIUGC. 
H17: Social trust will have a positive impact on altruism.

15) Perceived Risk (PR). Perceived risk refers to the uncertainty of one's behavioral outcomes. When users use the MIUGC platform, in addition to perceiving the expected factors, they also need to assess the damage. Thus, we hypothesize

H18: Perceived risk will have a negative impact on the MIUGC.

\section{Methodology and Results}

\subsection{Methodology.}

In order to test the proposed hypotheses, a sampling questionnaire was designed mainly based on the existing literature to ensure scientificity and effectiveness. According to what Churchill ${ }^{[6]}$ proposed, specific option concepts are supposed to be expressed and measured by at least two or more questions in the questionnaire. The scale uses the Likert 5-point method. The questionnaire consists 50 statements and was distributed randomly nationwide (online and offline). Finally, 408 valid samples were obtained.

Reliability was calculated for all multi-item variables. Cronbach's alphas for all variables were above the recommended level of 0.80 for field research, proving that the scale has good reliability. Through factor analysis, the factor loadings were greater than 0.50 , indicating high construct validity. We use a series of multiple regression analyses to test the above hypotheses.

\subsection{Results.}

Four multiple regression models were established. In Model 1, the dependent variable is MIUGC while the independent variables are personality traits, need for cognition, self-efficacy, willingness to express and record, self-worth, altruism, external benefits, perceived usefulness, perceived ease of use, perceived entertainment, social influence, social interaction, social identity, social trust and perceived risk. In Model 2, the dependent variable is perceived ease of use while the independent variable is self-efficacy. In Model 3, the dependent variable is perceived usefulness while the independent variable is perceived ease of use. In Model 4, the dependent variable is altruism while the independent variable is social trust. The regression results of Model 1 to Model 4 are shown in Table 1.

Table1 Results of multiple regression analysis

\begin{tabular}{|c|c|c|c|c|}
\hline \multirow{3}{*}{ Independent variables } & \multicolumn{4}{|c|}{ Dependent variables } \\
\hline & $\operatorname{MIUGC}\left(\mathrm{R}^{2=} 0.540\right)$ & $\operatorname{PEU}\left(\mathrm{R}^{2=} 0.290\right)$ & $\mathrm{PU}\left(\mathrm{R}^{2=} 0.307\right)$ & $\mathrm{AL}\left(\mathrm{R}^{2=} 0.243\right)$ \\
\hline & Beta(Model 1) & Beta(Model 2) & Beta(Model 3) & Beta(Model 4) \\
\hline $\mathrm{PT}$ & not support hypothesis & & & \\
\hline $\mathrm{NC}$ & $0.170 * *$ & & & \\
\hline SE & $0.168 * *$ & $0.539 * * *$ & & \\
\hline WER & $0.433 * *$ & & & \\
\hline SW & $0.107 *$ & & & \\
\hline AL & $0.206^{* *}$ & & & \\
\hline EB & $0.132 * *$ & & & \\
\hline PU & $0.284 * * *$ & & & \\
\hline PEU & not support hypothesis & & $0.554 * * *$ & \\
\hline $\mathrm{PE}$ & $0.247 * *$ & & & \\
\hline SIF & $0.145^{* *}$ & & & \\
\hline SIT & $0.227 * * *$ & & & \\
\hline SID & $0.118 * *$ & & & \\
\hline $\mathrm{ST}$ & $0.145^{* *}$ & & & $0.493 * * *$ \\
\hline PR & $-0.102 * *$ & & & \\
\hline
\end{tabular}

Note: ${ }^{*}<<0.05,{ }^{* *} \mathrm{p}<0.01,{ }^{* * *} \mathrm{p}<0.001$. 
In model 1, all hypotheses, except for hypotheses $\mathrm{H} 1$ and H8, were supported by the data. Variables including need for cognition, self-efficacy, willingness to express and record, self-worth, altruism, external benefits, perceived usefulness, perceived entertainment, social influence, social interaction, social identity, social trust and perceived risk are all significant. Moreover, the tolerance values of the above variables are all above 0.5 , and the VIF values are all below 2 , not more than 10 , indicating that the multivariate collinearity among the independent variables entering the regression equation is not obvious. In model2, model3 and model4, all variables are significant, indicating the hypotheses H10, H11 and H17 are supported.

\section{Discussion \& Conclusion}

This study analyzed the motivation of MIUGC through investigating the factors that influence MIUGC. In the dimension of subject level, the variable of personality traits has no significant influence on MIUGC. Although some studies have found that extraverted are more likely to generate content on the Internet, the introvert may feel a covering layer in the mobile Internet so that they can even change their true self in the virtual world, presenting a different aspect from its own personality. Cognitive style, self-efficacy, willingness to expressing \& recording, self-value, altruism and external benefits are found to impact on MIUGC positively. Self-efficacy is an important variable in the TAM model. In this study, it also reflects its impact on MIUGC. The more self-confident the users are about MIUGC, the easier they feel the use of MIUGC apps, and thus the more content they can generate. With relatively low self-efficacy, users may have a negative attitude toward MIUGC, and thus are less motivated to use it, which will hinder their MIUGC.

In terms of system perception, the predicted direct effect of perceived ease of use on MIUGC was not supported. The reason may be that the current MIUGC platform focuses more on simplicity and user-friendliness in function design, with high level of ease of use, making the factor not significant. And perceived entertainment and perceived usefulness are found to impact on MIUGC positively.

In terms of social relations, social influence, social interaction, social identity and social trust all have a positive impact on MIUGC. People have their own social needs in the social environment. Therefore, mobile internet users will hope to strengthen their social contacts and improve their social identity through MIUGC. The increase of social trust will intensify user's behavior of MIUGC.

At the same time, this study also tested the obstacles of MIUGC, and derived the variable of perceived risk, which has a negative effect on MIUGC. Perceived risk is a negative motivation of MIUGC. Mobile Internet users often consider risk factors such as time, equipment, security, and economy, which may make users unwilling to generate content. The higher the risk is, the less willingness users have. MIUGC service providers should guard against these risks, ensure system security, not carry out unreasonable deductions, and protect users’ privacy.

\section{Acknowledgements}

This work was financially supported by the Heilongjiang Postdoctoral Sustentation Fund, China (LBH-Z15116) and Heilongjiang Young Innovative Talents Training Program for Colleges and Universities (UNPYSCT-2016057).

\section{References}

[1] Gustav J C. Types psychologiques[J]. Genève, Georg, 1921.

[2] Kwok J S H, Gao S. Knowledge sharing community in P2P network: a study of motivational perspective [J]. Journal of Knowledge Management, 2004, 8(1): 94-102.

[3] Wei T T, Marthandan G, Chong A Y L, et al. What drives Malaysian m-commerce adoption? An empirical analysis [J].Industrial Management \& Data Systems, 2009,109(3):370-388.

[4] Agarwal R, Karahanna E. Time flies when you're having fun: Cognitive absorption and beliefs 
about information technology usage[J]. MIS quarterly, 2000: 665-694.

[5] Cook J, Wall T. New work attitude measures of trust, organizational commitment and personal need non-fulfilment[J]. Journal of occupational psychology, 1980, 53(1): 39-52.

[6] Churchill.G.A. A Paradigm for Developing Better Measures of Marketing Constructs [J]. Journal of Marketing Research. 1979(16):54-67 